$811.131 .1^{\prime} 367.625$

$811.163 .41^{\prime} 367.625$

https://doi.org/10.18485/primling.2019.20.4

Оригинални научни рад

Примљен: 23.05.2019

Прихваћен: 14.09.2019

\title{
Nataša Janićijević
}

Univerzitet u Beogradu

Filološki fakultet

\section{FUTURSKA UPOTREBA ITALIJANSKOG KONJUNKTIVA PREZENTA I NJEGOVI SRPSKI EKVIVALENTI}

Sažetak: U radu se proučava upotreba italijanskog konjunktiva prezenta u funkciji izražavanja budućih radnji. Osnovni cilj rada jeste da se utvrdi u kojim slučajevima, odnosno u kakvom sintaksičko-semantičkom okruženju, konjunktiv prezenta može imati futursko značenje. Što se dopunskih rečenica tiče, razmatra se kojim semantičkim klasama mogu pripadati glagoli uz koje konjunktiv prezenta ima referencu na budućnost, a potom se analizira njegova futurska upotreba i u ostalim vrstama zavisnih rečenica. Budući da srpski jezik u svom glagolskom sistemu ne poseduje oblik konjunktiva, drugi cilj rada jeste da se utvrde odgovarajući srpski ekvivalenti konjunktiva prezenta kao jednog od alternativnih sredstava za obeležavanje budućnosti u italijanskom jeziku.

Ključne reči: italijanski, srpski, budućnost, zavisne rečenice, ekvivalenti.

\section{Uvod}

Za razliku od indikativa koji označava radnje i stanja koja se odnose na realnu i objektivnu stvarnost, konjunktiv je glagolski način čija su osnovna značenja modalna. On iskazuje radnje i stanja koja pripadaju sferi želje, nade, pretpostavke, sumnje, potrebe, bojazni i različitih emotivnih stanja (sreća, tuga, stid itd.), kao i radnje i stanja čije je ostvarenje najčešće neizvesno, moguće ili nemoguće.

Iako ima i samostalnu upotrebu, konjunktiv je karakterističan prvenstveno za zavisne rečenice čiji je subjekat različit od subjekta upravne. On se najčešće ostvaruje u dopunskim rečenicama uvedenim raznim glagolima i izrazima koji označavaju lični stav prema realizaciji radnje, 
kao i u pojedinim vrstama zavisnih rečenica čiji veznici zahtevaju njegovu upotrebu. Najvažniju ulogu u njegovoj distribuciji igraju, pre svega, semantički i sintaksički faktori, ali u pojedinim kontekstima, u kojima je moguće upotrebiti i indikativ, na izbor između ova dva glagolska načina često mogu uticati stil i registar. Kada je u pitanju pisani jezik i viši registar, prednost u upotrebi daje se konjunktivu, dok se u govornom jeziku može javiti i indikativ.

Konjunktiv u italijanskom jeziku ima četiri vremena: prezent, perfekat, imperfekat i pluskvamperfekat. On ne poseduje oblik futura, pa se u onom kontekstu koji zahteva njegovu upotrebu, za obeležavanje budućnosti koriste obično prost futur ili konjunktiv prezenta. Imajući u vidu činjenicu da je u italijanskom jeziku i konjunktiv prezenta jedan od markera za buduću radnju, prvi i osnovni cilj rada jeste da se utvrdi u kojim slučajevima odnosno u kakvom sintaksičko-semantičkom okruženju on može imati futursko značenje. Budući da srpski jezik nema oblik konjunktiva, drugi cilj rada jeste da se utvrde odgovarajući srpski ekvivalenti futurski upotrebljenog konjunktiva prezenta. Korpus na kome je vršeno istraživanje sastoji se od primera preuzetih iz gramatika italijanskog jezika, korpusa savremenog pisanog italijanskog jezika Coris Univerziteta $\mathrm{u}$ Bolonji, jednojezičnih rečnika i dvojezičnog italijansko-srpskog rečnika (Klajn 2003), iz štampe i s televizije, kao i iz usmene komunikacije sa izvornim govornicima.

Futurska upotreba konjunktiva prezenta slabo je obrađena u literaturi o savremenom italijanskom jeziku. U gramatikama italijanskog jezika ona je ili zanemarena (Dardano \& Trifone 1997) ili nedovoljno objašnjena i potkrepljena malim brojem primera. U većini gramatika se samo kratko pominje da konjunktiv prezenta može označavati buduće radnje i da tada ima funkciju prostog futura (Sensini 1997: 249, Salvi \& Vanelli 2004: 253, Maiden \& Robustelli 2007: 335) ili, obrnuto, da se uz pojedine glagole i izraze koji zahtevaju konjunktiv može upotrebiti prost futur (Serianni 1989: 558, Salvi \& Vanelli 2004: 253, Patota 2006: 124, Maiden \& Robustelli 2007: 293). U svim navedenim gramatikama i prost futur i konjunktiv prezenta upotrebljeni su u primerima s dopunskom rečenicom, ali se ni u jednoj od njih ne navodi uz koje tačno glagole i izraze oni mogu biti međusobno zamenljivi odnosno uz koje tačno glagole i izraze konjunktiv prezenta može označavati buduće radnje. Za razliku od ostalih gramatičara, Moretti \& Orvieto (1984) i Garigliano (2011) konstatuju da konjunktiv prezenta i prost futur mogu alternirati i u zavisno-upitnoj rečenici. 
Što se naučnih radova tiče, ne postoji nijedan koji obrađuje futursku upotrebu konjunktiva. U svom radu o upotrebama prostog futura, Berretta (1991: 137) samo kratko navodi da se budućnost može izraziti i konjunktivom prezenta u zavisnim rečenicama koje uvode glagoli sumnje/predviđanja ${ }^{\text {' }}$ i slični izrazi (non è escluso che 'nije isključeno da', ’̀ possibile che 'moguće je da'), kao i uopšte u zavisnim rečenicama koje se odnose na budućnost, što ilustruje primerima s konjunktivom prezenta u vremenskoj rečenici posle veznika prima che 'pre nego što' i namernoj posle veznika affinché 'da (+ prezent / potencijal)', 'kako (+ potencijal)'. Međutim, treba istaći da konjunktiv prezenta nema isto futursko značenje u dopunskoj rečenici uz glagole mišljenja, sumnje, nade i sl. i u namernoj rečenici koja je već po svom značenju modalna. Kada je u pitanju budućnost, treba praviti razliku između „pravih“ budućih radnji i modalnih radnji koje se samo žele, nameravaju i sl., a čije ostvarenje može biti usmereno ka budućnosti.

Iz svega do sad rečenog, vidi se da ni u gramatikama ni u naučnoj literaturi nisu dovoljno opisani ni sistematski obrađeni slučajevi u kojima konjunktiv prezenta može imati značenje budućeg vremena. U ovom radu pokušaćemo da pružimo detaljan i sistematizovan opis, tako što ćemo pojedinačno analizirati zavisne rečenice u kojima konjunktiv može iskazivati buduće radnje. Što se dopunskih rečenica tiče, razmotrićemo kojim semantičkim klasama mogu pripadati glagoli uz koje konjunktiv ima referencu na budućnost, a potom ćemo razmotriti njegovu futursku upotrebu i u ostalim vrstama zavisnim rečenicama.

\section{Sintaksička distribucija konjunktiva prezenta s futurskim značenjem}

Konjunktiv prezenta može iskazivati buduću radnju u dopunskoj rečenici uvedenoj glagolima koji iskazuju mišljenje, sumnju, pretpostavku, privid, lični utisak i sl. U ovu klasu glagola spadaju glagoli poput pensare 'misliti', credere 'verovati', dubitare 'sumnjati', supporre 'pretpostavljati', sembrare / parere 'činiti se', avere l'impressione 'imati utisak' i njima slični.

\footnotetext{
${ }^{1}$ Kao primer Berretta (1991: 137) navodi glagol sperare 'nadati se'. Treba istaći da ovaj glagol nije tipičan predstavnik epistemičkih značenja sumnje i predviđanja. Sumnja i predviđanje se najpre izražavaju raznim glagolima mišljenja, a sperare 'nadati se' nosi u sebi modalna značenje nade, želje i sl., i uvodi deontički modalizovane iskaze (v. Palmer 1986).
} 
(1) Penso che prima o poi vi trasferiate in un'altra città. (Garigliano 2011: 549)

'Mislim da ćete se kad-tad preseliti u drugi grad.'

(2) Credo che arrivino domani. (Patota 2006: 126)

'Verujem da stižu / će stići sutra.'

(3) Dubita che gli restituiscano i soldi. (Razg.)

'Sumnja da će mu vratiti pare.'

(4) Mi sembra che solo loro non partecipino domani alla gara. (Razg.)

'Čini mi se da samo oni ne učestvuju / neće učestvovati sutra na takmičenju.'

(5) Ho l'impressione che non venga più. (Coris: MON2001_04) 'Imam utisak da neće više doći.'

(6) Si suppone che tornino il 20. (Razg.)

'Pretpostavlja se da se vraćaju / će se vratiti 20.'

Da u navedenim primerima konjunktiv prezenta ima značenje budućeg vremena, vidljivo je po tome što se svuda može zameniti prostim futurom.

U govornom italijanskom jeziku se iza pojedinih glagola mišljenja umesto konjunktiva može javiti indikativ. Takva upotreba indikativa dosta je stara, kao što je u svom radu dokazala F. Ageno (1961), a u savremenom govornom jeziku ona je sve raširenija, o čemu govore i pojedine gramatike italijanskog jezika (Serianni 1989, Patota 2006, Maiden \& Robustelli 2007), kao i druga stručna i naučna literatura (Berruto 1987, Berretta 1991, Wandruszka 1991, D’Achille 2003). Iako se u govornom jeziku i neformalnom registru uz pojedine glagole toleriše i indikativ, konjunktiv je svakako ispravniji oblik. Međutim, sama činjenica da se može javiti i indikativ govori u prilog tome da je konjunktiv uz mnoge glagole misljenja više gramatički i stilski izbor nego što je značenjski neophodan (v. Lepschy \& Lepschy 2000, Moretti \& Orvieto 1984, Serianni 1989). Nadovezujući se na Klajna (1980) koji pravi razliku između ,pravog“ konjunktiva, tj. onog koji iskazuje prave modalne radnje i „formalnog“ koji je to samo po obliku, možemo se složiti s njim da je ovako upotrebljen konjunktiv samo „formalni““. Pod tim svakako ne mislimo da konjunktiv 
u navedenim iskazima nema nikakvo modalno značenje, već da on ne iskazuje pravu modalnu, nego samo modalno obojenu radnju. Drugim rečima, modalnost celokupnog iskaza ne potiče od samog konjunktiva već od modalne semantike upravnog glagola. Naime, u svim navedenim primerima reč je o epistemički modalizovanim iskazima u kojima se govornik ne opredeljuje ni prema istinitosti ni prema neistinitosti propozicije. On samo izražava svoj subjektivni stav prema radnji zavisne rečenice, u smislu manjeg ili većeg stepena nesigurnosti, suzdržanosti, kolebanja, pretpostavke i sl. u vezi sa njenim ostvarenjem. Na govornikov stav već ukazuje značenje upravnog glagola kome je konjunktiv samo formalna dopuna. U to se lako možemo uveriti ako izmenimo sintaksičku strukturu rečenice, a upravni glagol zamenimo odgovarajućom parafrazom koja zahteva upotrebu indikativa: (1a) Secondo me, prima o poi vi trasferirete in un'altra città 'Po mom mišljenju, kad-tad ćete se preseliti u drugi grad'; (4a) A quanto mi sembra, solo loro non partecipano domani alla gara 'Kako mi se čini, samo oni ne učestvuju sutra na takmičenju'; (6a) $A$ quanto si suppone, tornano il 20 'Po onome što se pretpostavlja, vraćaju se 20.' U navedenim primerima i rečenice sa konjunktivom i rečenice sa indikativom (prezenta ili futura) imaju isti stepen nefaktivnosti i isto značenje. Celokupan iskaz je epistemički modalizovan, a sam konjunktiv ima prvenstveno vremensko značenje, i to značenje budućnosti.

Odgovarajući srpski ekvivalenti ovako upotrebljenog konjunktiva prezenta jesu futur I i prezent za budućnost, ukoliko je njegova upotreba moguća u datom kontekstu. Ovakav konjunktiv Klajn (1980) naziva „neprevedenim“ jer njegov odraz u srpskom jeziku nije neki modalni oblik.

Konjunktiv prezenta može označavati buduću radnju i u subjekatskoj rečenici iza bezličnih izraza è possibile che 'moguće je da', è probabile che 'verovatno je da', è impossibile 'nemoguće je da', è improbabile che 'malo je verovatno da', può darsi 'može biti', è difficile che 'teško da', non è escluso che 'nije isključeno da', koji takođe uvode epistemički modalizovane iskaze. I ovde se konjunktiv prezenta može zameniti prostim futurom onda kada je potencijalna radnja definitivno smeštena u budućnosti.

(7) È possibile che domani la sinistra voti contro. (dnevnik TG 1)

'Moguće je da levica sutra glasa protiv / da će levica sutra glasati protiv.'

(8) È molto probabile che stasera ti accompagnino alla stazione. (Razg.) 'Vrlo je verovatno da će te večeras otpratiti na stanicu.' 
(9) È difficile che torni oggi. (Klajn 2003)

'Teško da će se danas vratiti.'

(10) Siccome sbaglia tanto (...), può darsi che alla fine perda. (Coris:

MON2001_04)

'Pošto toliko greši (...), može biti da će na kraju izgubiti.'

Odgovarajući srpski ekvivalenti ovako upotrebljenog konjunktiva prezenta jesu futur I, a ponekad i prezent.

Konjunktiv prezenta može biti futurski marker i uz glagole koji označavaju nadu i strah, kao što su sperare 'nadati se' i temere 'bojati se', kao i njima slični izrazi nutrire la speranza 'gajiti nadu', avere paura 'plašiti se' i drugi. Za razliku od svih prethodnih iskaza, koji su epistemički modalizovani, iskazi s ovim glagolima spadaju u deontičku modalnost (v. Palmer 1986).

(11) Spero che tu gli dia una mano a fare quel lavoro. (Vanelli 1991: 615) 'Nadam se da ćeš mu pomoći da uradi taj posao.'

(12)(...)nutrolasperanzachedalpagliaiospuntiall'improvvisol'agoperduto. (Coris:NARRATRomanzi)

'(...) gajim nadu da će se u plastu sena iznenada pojaviti izgubljena igla.'

(13) Temo che non ci riescano. (Coris: NARRATRoma)

'Bojim se da neće uspeti.'

(14) Ho una gran paura che ci scoprano e ci fucilino. (Coris: NARRATVaria)

'Strašno se plašim da će nas otkriti i streljati / da nas ne otkriju i ne streljaju.'

(15) Hanno paura che l'edificio gli caschi addosso. (Maiden \& Robustelli 2007: 317)

'Boje se da će zgrada pasti na njih / da zgrada ne padne na njih.'

I u ovim iskazima konjunktiv prezenta može alternirati s prostim futurom. Njegov odgovarajući srpski ekvivalent jeste futur I. Uz glagole i izraze koji označavaju strah, bojazan može se upotrebiti i odrični oblik perfektivnog prezenta. On je sinoniman s futurom I, a njegov odrični oblik je logički suprotan onome što se želi reći (v. Klajn 1980). 
Konjunktiv prezenta može imati vrednost budućeg vremena i uz pojedine glagole i izraze koji iskazuju emotivni stav (sreća, zadovoljstvo, žaljenje, čuđenje, ljutnja i sl.) prema radnji zavisne rečenice. Tako upotrebljen konjunktiv ilustruju sledeći primeri:

(16) Sono contento che venga presto. (Lepschy \& Lepschy 2000: 205) 'Srećan sam što uskoro dolazi.'

(17) Mi dispiace che fra poco ci separiamo. (Coris: MON2005_07) 'Žao mi je što se uskoro rastajemo.'

(18) Il matrimonio del suo migliore amico è fra tre giorni e mi fa rabbia che lui non ci vada. (Razg.)

'Venčanje njegovog najboljeg druga je za tri dana i ljutim se što on ne ide.'

(19) Sono deluso che non rimangano da noi anche per il fine settimana. (Razg.)

'Razočaran sam što ne ostaju kod nas i za vikend.'

I uz ove glagole i izraze konjunktiv prezenta bi mogao da se zameni prostim futurom. Navedeni primeri, kao i drugi slični koje smo analizirali, navode na zaključak da je prost futur uobičajeniji onda kada se radnja odnosi na dalju budućnost, a konjunktiv prezenta onda kada ona pripada bliskoj budućnosti i kada je ugovorena, dogovorena, očekivana i sl.

Za razliku od prethodne dve grupe glagola, glagoli koji iskazuju emotivni stav prema radnji spadaju u faktivne predikate (v. Palmer 1986). Oni impliciraju govornikovo opredeljenje prema istinitosti propozicije i njihova karakteristika je da uvode realne, činjenične radnje, ali obično zahtevaju konjunktiv jer se njima izražavaju lični stav i reakcija prema radnji zavisne rečenice. U srpskom jeziku rečenice uvedene ovim predikatima imaju veznik ,ک̌to“ i pripadaju uzročnim, dok su u italijanskom one po obliku subjekatske ili objekatske, a po značenju dosta bliske uzročnim. Da su iskazi s navedenim glagolima faktivni, potvrđuje i činjenica da se ovakve rečenice mogu parafrazirati sa il fatto che '(to) što': Mi fa piacere che tu venga / Mi fa piacere il fatto che tu venga (Salvi \& Vanelli 2004: 258) 'Drago mi je što dolaziš'. Uz ove glagole u pisanom jeziku i formalnom registru poželjna je upotreba konjunktiva, dok je u govoru uobičajen indikativ. 
Odgovarajući srpski ekvivalent konjunktiva prezenta u navedenim primerima je prezent. Osim prezenta, odgovarajući ekvivalent bi mogao da bude i futur I.

Što se subjekatskih i objekatskih rečenica tiče, konjunktiv prezenta može imati funkciju označavanja buduće radnje samo onda kada se upotrebi kao dopuna do sad navedenim vrstama glagola. Kao što smo već istakli, uz sve ove glagole on je komutabilan s prostim futurom.

Konjunktiv prezenta može imati pravo futursko značenje i u zavisno-upitnoj rečenici, što ilustruju sledeći primeri:

(20) Nessuno sa se venga. (Fava 1991: 705)

'Niko ne zna da li dolazi.'

(21) Non sono certo se partecipino domani alla gara. (Razg.)

'Nisam siguran da li sutra učestvuju na takmičenju.'

Umesto konjunktiva prezenta i ovde se može upotrebiti prost futur. Konjunktiv se, inače, može javiti u zavisno-upitnim rečenicama jer je reč o pitanju, o nečemu što je nepoznato i neizvesno. Međutim, njegova upotreba u ovom tipu rečenice uglavnom zavisi od stilskih faktora i jezičkog registra. On se je karakterističan za pisani jezik i formalni registar, dok se u govoru uglavnom upotrebljava indikativ.

Konjunktiv prezenta može imati vrednost futura i u dopusnim rečenicama, što ilustruju sledeći primeri:

(22) Ti saluto adesso, nonostante tu parta solo fra una settimana. (Vanelli 1991: 615)

'Pozdravljam te sada, iako putuješ tek za nedelju dana.'

(23) Sebbene venga a trovarmi solo fra una settimana, non la rimprovererò quando arriverà. (Ibid: 629)

'Iako će me posetiti tek za nedelju dana, neću je izgrditi kad dođe.'

(24) Benché Piero ci lasci fra un mese, non gli faremo nessuna festa. (Ibid: 632)

'Iako na Pjero napušta tek za mesec dana, nećemo mu napraviti nikakvu proslavu.'

Po svom značenju dopusne rečenice nisu modalne jer se odnose na realne i objektivne radnje. Međutim, veznici koji ih uvode zahtevaju 
konjunktiv, tako da je njegova upotreba u ovom tipu rečenice uslovljena isključivo sintaksičkim faktorima. Jedini izuzeci u pogledu veznika jesu anche se 'iako', 'mada', 'premda' i manje frekventni con tutto che 'iako', 'mada', 'premda', koji uvode predikat u indikativu.

Kada je reč o budućoj radnji, Vanelli (1991: 615, 627, 629, 632) na više mesta ističe da dopusni veznici koji zahtevaju konjunktiv ne dozvoljavaju upotrebu prostog futura za izražavanje budućnosti, već isključivo konjunktiva prezenta s futurskom vrednošću. I Maiden \& Robustelli (2007: 293) odriču mogućnost upotrebe prostog futura umesto konjunktiva prezenta. Nasuprot njima, Serianni (1989: 599) tvrdi da je uz benché 'iako', 'mada', 'premda', kao i uz ostale dopusne veznike, uvek moguća upotreba prostog futura za označavanje radnji koje su posteriorne radnji upravne rečenice, što potkrepljuje sledećim Pirandellovim primerom: ${ }^{2}$, ,ah, ma mi congratulo lo stesso, benché forse per me ne dipenderà la perdita d'una cara compagna. "I mi smo u raznim primerima s televizije i iz štampe naišli na upotrebu prostog futura u dopusnoj rečenici, a ovde navodimo samo sledeća dva:

(25) La Sicilia sarà raggiunta dal peggioramento nella giornata di oggi, sebbene sarà domani il giorno più brutto. (dnevnik TG 1)

'Siciliju će tokom današnjeg dana zahvatiti pogoršanje, iako će najgori dan biti sutra.'

(26) Un giorno, in futuro, il petrolio finirà, sebbene continuerà a giocare un ruolo chiave nella produzione di energia per molti anni. (La Stampa 14/09/2010)

'Jednog dana, u budućnosti, nafte više neće biti, iako će i dalje igrati ključnu ulogu u proizvodnji energije još mnogo godina.'

Primer koji navodi Serianni (1989), kao i ovi naši, dokazuju da upotreba prostog futura nije potpuno isključena uz dopusne veznike s konjunktivom, kao što tvrdi Vanelli (1991). Stoji, međutim, činjenica da on ne može zameniti konjunktiv prezenta u primerima koje ona daje, kao i u drugim sličnim. S obzirom na to da se prost futur ipak može javiti uz dopusne veznike koji inače traže konjunktiv, mišljenja smo da dodatno treba ispitati pod kojim uslovima se on uz njih može upotrebiti. Na osnovu raznih primera koje smo analizirali, čini nam se da upotreba prostog

${ }^{2}$ Pirandello, L. Il giuoco delle parti, III, 86. 
futura nije moguća onda kada je buduća radnja isplanirana i ugovorena, kao u primerima (22)-(24), u kojima on ima sličnu funkciju kao indikativ prezenta za budućnost, a da se, pak, može javiti u nekim drugim kontekstima koji se odnose na budućnost. Moguće je, takođe, da na upotrebu konjunktiva prezenta i prostog futura utiču donekle i akcionalna obeležja glagola. U primeru koji navodi Serianni, kao i u primeru (25) upotrebljeni su stativni glagoli, koji se inače, kako navodi Vanelli (1991: 629), ne javljaju u prezentu za budućnost ${ }^{3}$, dok se u primeru (26) nalazi kontinuativni glagol. Ukoliko bi se u njegovom primeru upotrebio konjunktiv prezenta dipenda radnja bi se odnosila na sadašnjost. Isto tako bi se u primeru (26) konjunktiv prezenta continui a giocare 'i dalje igra' odnosio na sadašnjost, s tim što on ne bi ni mogao da se upotrebi jer bi bio inkompatibilan s vremenskom odredbom per molti anni 'još mnogo godina', koja upućuje na budućnost. I u primeru (25) nalazi se stativni glagol, a pritom je reč o vremenskoj prognozi, koja se ne mora nužno obistiniti, tako da je i gramatički i semantički ispravnija upotreba prostog futura. Ako bi se ovde upotrebio prezent, radnja bi se odnosila na sadašnjost, i otuda futur. Kako smo već istakli, potrebno je dodatno ispitati kakve su stvarno mogućnosti upotrebe prostog futura uz dopusne veznike koji inače uvode konjunktiv i od čega one zavise.

Kao što se na osnovu prevoda vidi, odgovarajući srpski ekvivalenti datog konjunktiva prezenta jesu prezent za budućnost i futur I.

Za označavanje buduće radnje u vremenskoj rečenici upotrebljavaju se oblici indikativa, i to najčešće prost ili anteriorni futur, a u govornom jeziku i prezent, a ponegde i složeni perfekat. Ukoliko se, međutim, buduća radnja smatra mogućom ili neizvesnom, ona se može izraziti i konjunktivom prezenta. Ovakva upotreba konjunktiva prezenta svojstvenija je formalnom registru, a ovde je ilustruju sledeći primeri:

(27) Quando tu decida di trasferirti, ti aiuteremo volentieri. (De Mauro 2000)

'Kada budeš odlučio / odlučiš da se preseliš, rado ćemo ti pomoći'

\footnotetext{
${ }^{3}$ Po pravilu, stativni glagoli se ne mogu upotrebiti u prezentu za budućnost ( ${ }^{\star}$ Domani sono felice 'Sutra sam srećan') već isključivo u prostom futuru (Domani sarò felice 'Sutra ću biti srećan’). Međutim, na osnovu raznih primera koje smo analizirali, došli smo do zaključka da se ovi glagoli ipak mogu javiti i u prezentu za budućnost, ali u veoma ograničenim kontekstima. Takva njihova upotreba moguća je ako je u pitanju isplanirana, ugovorena, izvesna radnja (Domani sono libero tutto il pomeriggio 'Sutra sam slobodan celo popodne') ili ako je govornik čvrsto uveren da će se radnja ostvariti, pa je predstavlja kao neminovnu, neizbežnu (Abbiamo lasciato la porta aperta. Se le bestie entrano, è la fine. (Coris: MON 2005_07) 'Ostavili smo otvorena vrata. Ako zveri uđu, to je kraj.').
} 
(28) Aspetterò fino a che non arrivi. (Ibid)

'Sačekaću dok ne bude došao / ne dođe.'

(29) Non appena tu guarisca, partiremo per la montagna. (Wandruszka 1991: 458)

'Čim budeš ozdravio / ozdravišs, otputovaćemo na planinu.'

Ukoliko je vremenska rečenica uvedena veznikom prima che 'pre nego što', neophodna je upotreba konjunktiva.

(30) Ti chiamerò prima che tu esca. (Razg.)

'Zvaću te pre nego budeš izašao / izađeš.'

U srpskom jeziku se u vremenskoj rečenici za obeležavanje buduće radnje upotrebljavaju futur II i perfektivni prezent tako da ovi glagolski oblici predstavljaju odgovarajuće ekvivalente datog konjunktiva prezenta.

\section{Zaključak}

Premda u italijanskom jeziku primarno značenje konjunktiva prezenta nije futursko, u određenim sintaksičko-semaničkim okolnostima i ovaj glagolski oblik može izražavati buduće radnje. Kako smo u ovom istraživanju pokazali, njegova futurska upotreba ostvaruje se samo u određenim vrstama zavisnih rečenica i to: subjekatskoj, objekatskoj, zavisnoupitnoj, dopusnoj i vremenskoj rečenici. U ostalim vrstama zavisnih rečenica za obeležavanje budućnosti upotrebljavaju se prost futur ili drugi glagolski oblici koji u datom kontekstu imaju značenje buduće radnje.

U italijanskom jeziku konjunktiv prezenta se javlja i u raznim drugim vrstama zavisnih rečenica u kojima njegovu upotrebu diktira određeni veznik i/ili modalno značenje same rečenice. Budući da u takvim upotrebama konjunktiv prezenta nema futursko značenje, one izlaze iz domena ovog istraživanja i ovde nisu analizirane.

Poznato je da srpski jezik nema konjunktiv kao posebnu morfološku kategoriju, ali poseduje druga jezička sredstva za prenošenje njegovih semantičkih vrednosti, pri čemu primarnu ulogu imaju pojedina glagolska vremena, kao i glagolski načini. U skladu sa ovim istraživanjem pažnja je bila posvećena samo futurskoj upotrebi italijanskog konjunktiva prezenta, 
a njegove odgovarajuće srpske ekvivalente predstavljaju futur I, prezent, a u vremenskoj rečenici i futur II odnosno perfektivni prezent.

\section{Literatura}

Ageno, F. (1961). Indicativo in dipendenza da «credere» e sinonimi. Lingua nostra 22: 6-8. 140.

Berretta, M. (1991). Parliamo del nostro futuro. Italiano e Oltre 6/3: 135-

Berrutto, G. (1987). Sociolinguistica dell'italiano contemporaneo. Roma: La Nuova Italia Scientifica.

CORIS - Corpus dell'italiano scritto. Facoltà di Lettere e Filosofia, Università di Bologna, http://corpora.dslo.unibo.it/coris_ita.html.

Dardano, M. \& P. Trifone (1997). La nuova grammatica della lingua italiana. Bologna: Zanichelli Editore.

D'Achille, P. (2003). L'italiano contemporaneo. Bologna: Il Mulino.

De Mauro, T. (2000). Il dizionario della lingua italiana. Milano: Paravia Bruno Mondadori Editore.

Fava, E. (1991). Interrogative indirette. In: Grande grammatica italiana di consultazione. Volume II: I sintagmi verbale, aggettivale, avverbiale. La subordinazione (L. Renzi \& G. Salvi, eds.), Bologna: Il Mulino, 675-720.

Garigliano, P. (2011). Trattato di grammatica italiana e analisi logica. Catania: C.U.E.C.M.

Klajn, I. (1980). Italijanski konjunktiv i njegovo prevođenje na srpskohrvatski. Studije iz kontrastivne analize italijanskog i srpskohrvatskog jezika. Beograd, Filološki fakultet, 83-101.

Klajn, I. (2003). Italijansko-srpski rečnik. Beograd: Nolit.

Lepschy, A. L. \& G. C. Lepschy (2000). La lingua italiana. Storia, varietà dell'uso, grammatica. Milano: Bompiani.

Maiden, M. \& C. Robustelli (2007). A Reference Grammar of Modern Italian. London: Hodder Publications.

Moretti, G. B. \& G. R. Orvieto (1984). Grammatica italiana. Il verbo, vol. I. Perugia: Editrice Benucci (3. izdanje; 1. izdanje: 1979).

Palmer. F.R. (1986). Mood and modality. Cambridge: Cambridge University Press.

Patota, G. (2006). Grammatica di riferimento dell'italiano contemporaneo. Novara: Garzanti Linguistica.

Salvi, G. \& L. Vanelli (2004). Nuova grammatica italiana. Bologna: Il Mulino. 
Sensini, M. (1997). La grammatica della lingua italiana. Milano: Arnoldo Mondadori.

Serianni, L. (1989). Grammatica italiana. Italiano comune e lingua letteraria. Torino: UTET.

Vanelli, L. (1991). La concordanza dei Tempi. In: Grande grammatica italiana di consultazione. Volume II: I sintagmi verbale, aggettivale, avverbiale. La subordinazione (L. Renzi \& G. Salvi, eds.), Bologna: Il Mulino, 611-632.

Wandruszka, U. (1991). Frasi subordinate al congiuntivo. In: Grande grammatica italiana di consultazione. Volume II: I sintagmi verbale, aggettivale, avverbiale. La subordinazione (L. Renzi \& G. Salvi, eds.), Bologna: Il Mulino, 415-481.

\section{Nataša Janićijević \\ FUTURE TIME USE OF THE ITALIAN PRESENT SUBJUNCTIVE AND ITS SERBIAN EQUIVALENTS}

Summary: The basic meanings of the Italian present subjunctive are modal. It serves primarily to express a wide range of notions such as wishes, hopes, assumptions, doubts, necessity, uncertainty, probability, etc. However, in certain contexts, this form can also be used to express future events. In this paper we determine in which specific syntactic and semantic environment, i.e. in which types of subordinate clauses the present subjunctive can express future time reference. We show that, as an alternative marker of futurity, the present subjunctive occurs exclusively in certain types of subordinate clauses, namely complement clauses, indirect interrogative, concessive and temporal clauses, in which it can always alternate with the future simple tense. In the paper we also point out the adequate Serbian equivalents of the present subjunctive as one of the alternative devices for marking future time reference in Italian.

Key words: Italian, Serbian, future time, dependent clauses, equivalents. 